\title{
Comparative Clinical Study of Local Submucosal Corticosteriod Versus Diclofenac Sodium Injections Before Odontectomy of Mandibular Impacted Third Molar
}

\author{
Ahmed Mohamed El Zayat ${ }^{1}$, Eman Abdelhalem El Sharrawy ${ }^{2}$, Amr Ali El Swify², \\ Abdel Bade Abd Allah Abdel Maabod ${ }^{2}$ \\ ${ }^{1}$ Oral \& Maxillofacial Surgery Department, Insurance Hospital, Suez, Egypt \\ ${ }^{2}$ Oral \& Maxillofacial Surgery Department, Faculty of Dentistry, Suez Canal University, Ismailia, Egypt
}

Email address:

Ahmedelzayat84@yahoo.com (A. M. El Zayat), Amrswify@gmail.com (A. A. El Swify)

To cite this article:

Ahmed Mohamed El Zayat, Eman Abdelhalem El Sharrawy, Amr Ali El Swify, Abdel Bade Abd Allah Abdel Maabod. Comparative Clinical Study of Local Submucosal Corticosteriod Versus Diclofenac Sodium Injections Before Odontectomy of Mandibular Impacted Third Molar. International Journal of Clinical Oral and Maxillofacial Surgery. Vol. 4, No. 1, 2018, pp. 19-24. doi: 10.11648/j.ijcoms.20180401.14

Received: April 17, 2018; Accepted: May 2, 2018; Published: June 2, 2018

\begin{abstract}
The aim of this comparative clinical study was to investigate the effects of preoperative injections of Dexamethasone Sodium Phosphate versus Diclofenac Sodium. The study includes 60 patients (age range 16-35) who were randomly distributed into three equal groups. Edema and trismus was measured preoperatively, immediate, $24 \mathrm{~h}, 2$ week, 1 month postoperatively. Pain was assessed by visual analogue scale. Noteworthy reduction in postoperatively complication associated with Dexamethasone group was noticed. Edema \& trismus in control group was greater followed by Diclofenac groups then group I. Pain was greater score in control group followed by Diclofenac group then group I.
\end{abstract}

Keywords: Preoperative Injection, Submucosal, Corticosteriod, Diclofenac Sodium, Mandibular Impacted Third Molar

\section{Introduction}

Surgical removal of impacted third molars causes many injuries to surrounding tissues producing pain, acute inflammation and trismus. [1,2] Several studies discussed treatments to reduce postoperative complications by using antiseptic mouthwashes, use of drains, flap design, antibiotics, corticosteroid treatment, muscle relaxant and physiotherapy. [3-5]

Many studies compared effects of corticosteroids and NSAIDs in reduction of complications of surgical removal of impaction tooth such as pain, trismus, and edema. [6-12] The analysis of results of these studies supported the hypothesis that preemptive corticosteroids and NSAIDs were effective in delaying and preventing many postoperative sequelae. [13, 14] The aim of the present study was to compare between effectiveness submucosal injection of Diclofenac Sodium versus Dexamethasone Sodium Phosphate on postoperative pain, edema and trismus after odontectomy of mandibular third molar.

\section{Patients and Methods}

\subsection{Patients Selection}

Sixty patients were included in this prospective randomized study. They were selected from outpatient clinic of Oral \& Maxillofacial Surgery Department Faculty of Dentistry in Suez Canal University. All patients were informed of the methodology and signature of approval consent form. Complete medical history was taken for every patient.

Inclusion criteria: Patients requiring surgical extraction under local anaesthesia for single impacted lower third molar with winter class II \&III and position B \& C according to Pell \& Gregory classification. American Society of Anesthesiologists classification (ASA) I healthy patients.

\subsection{Exclusion Criteria}

Any pathological clinical conditions related to the mandibular third molar. Patient had acute infection related to 
lower impacted third molar. Any contraindication for oral surgery and administration of NSAIDs or corticosteroids drugs. Pregnant \&lactating women were excluded from this study. Patients have any contraindications for oral surgery and administration of NSAIDs or corticosteroids drugs. Pregnant \&lactating women were excluded from this study.

Sixty patients were distributed randomly into three equal groups according drugs were used in study: Group I: preoperative submucosal injection of dexamethasone sodium phosphate $4 \mathrm{mg} / 1 \mathrm{ml}$ ( $2 \mathrm{ml}$ Epidron ampoules) at surgical area. Group II: preoperative submucosal injection of diclofenac sodium 75mg / 3ml (voltaren ampoules). Group III: control group was injected with preoperative submucosal saline.

\subsection{Used Drugs}

Dexamethasone Sodium Phosphate, EPIDRON® ${ }^{\circledR} \mathrm{mg} / \mathrm{ml}$ vial, E.I.P.I.CO., Egypt. Diclofenac Sodium, VOLTAREN ${ }^{\circledR}$ $75 \mathrm{mg} / 3 \mathrm{ml}$ amp. NOVERTIS.

\subsection{Preoperative Assessment: Baseline Measurements}

\subsubsection{Facial Dimensions}

Patients were seated in upright position, upper and lower teeth in maximum intercuspation and determine the initial point at Gonion and extend five lines from this point to five points Pognion, Corner of mouth, Ala of nose, Outer angle of canthus and Tragus respectively by used black silk 3-0 (Figure 1). [15]

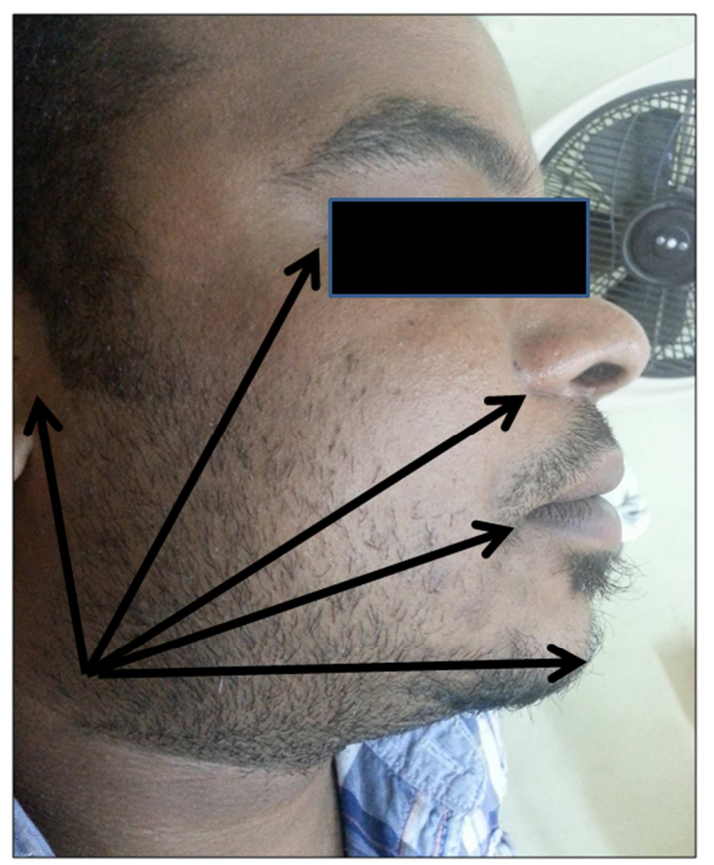

Figure 1. Clinical photographs showing the reference lines of facial edema measurements.

\subsubsection{Mouth Opening}

Measure maximum mouth opening with caliber by measure the interincisal distance when patient was in upright position.

\subsection{Operative Procedure}

[16] All surgical procedures were performed by the same surgeon using a standardized technique under aseptic condition. All patients received $0.125 \%$ chlorhexidine solution mouth rinse one minute before surgery. All patients were operated under local anesthesia using Articaine hydrochloride 4\% with 1:100,000 epinephrine. All patients were anesthetized by inferior alveolar, lingual \& long buccal nerve block techniques. The drugs used in study were infiltrated submucosally around the site of surgery at approximately $10 \mathrm{~min}$ before surgery. Incisions were made and mucoperiosteal flap was reflected with a periosteal elevator. Bone was removed to expose the impacted tooth with a surgical bur under continuous irrigation with saline. Sectioning the tooth was performed if necessary. The wound was sutured using a 3-0 silk suture. Sterile gauze pack was kept on the wound and the patient was given postoperative instructions and prescriptions for antibiotic (Amoxicillin trihydrate $875 \mathrm{mg}$ + Clavulanate potassium $125 \mathrm{mg}$ ) and rescue analgesic (Paracetamol $1000 \mathrm{mg}$ ) Sutures were removed after one week.

\subsection{Assessment of Edema}

Facial edema was measured immediate postoperatively, after 48 hour, after 7 days, after 2 weeks and after one month by measuring the distance between points which were determined in preoperative assessment ( from gonion extend fine lines to five points pognion, corner of mouth, ala of nose, outer angle of canthus and tragus respectively.[15]

\subsection{Assessment of Pain}

Pain was evaluated using 0-100 VAS that ranged from 0 "no pain" to 100 "the worst pain which was assessed $4 \mathrm{~h}, 8 \mathrm{~h}$, $12 \mathrm{~h}, 24$, 48hour postoperatively and how many tables of paracetamol are used within 48 hour.

\subsection{Assessment of Trismus}

Mouth opening (interincisor distance) is measured by using caliber immediate postoperatively, after 48 hour, after 7 days, after 2 weeks and after one month.

\section{Result}

60 patients were distributed into three groups, Group I (12 females and 8 males) group II (13 females and 7 males) group III (10 females and 10 males), no significant differences regarding gender. Age range was 18-35 years, no significant differences regarding age.

Assessment of edema by measuring five lines from gonion to pognion, corner of mouth, ala of nose, outer angle of canthus and tragus.

Comparing of mean and standard deviation (SD) of Gonion-Pognion ( $\mathrm{mm}$ ) showed highly significant differences $\mathrm{p} \leq 0.001$ in measures of Dexamethasone group $(10.37 \pm 0.69)$ in compared with control(11.70 \pm 1.44$)$ 
and Diclofenac(11.20 \pm 1.44 ) groups especially 48 hours postoperatively (figure 2)

Highly significance of differences $\mathrm{p} \leq 0.001$ in Gonion-
Corner of mouth measures between three groups after $24 \mathrm{~h}$ and 7 days.

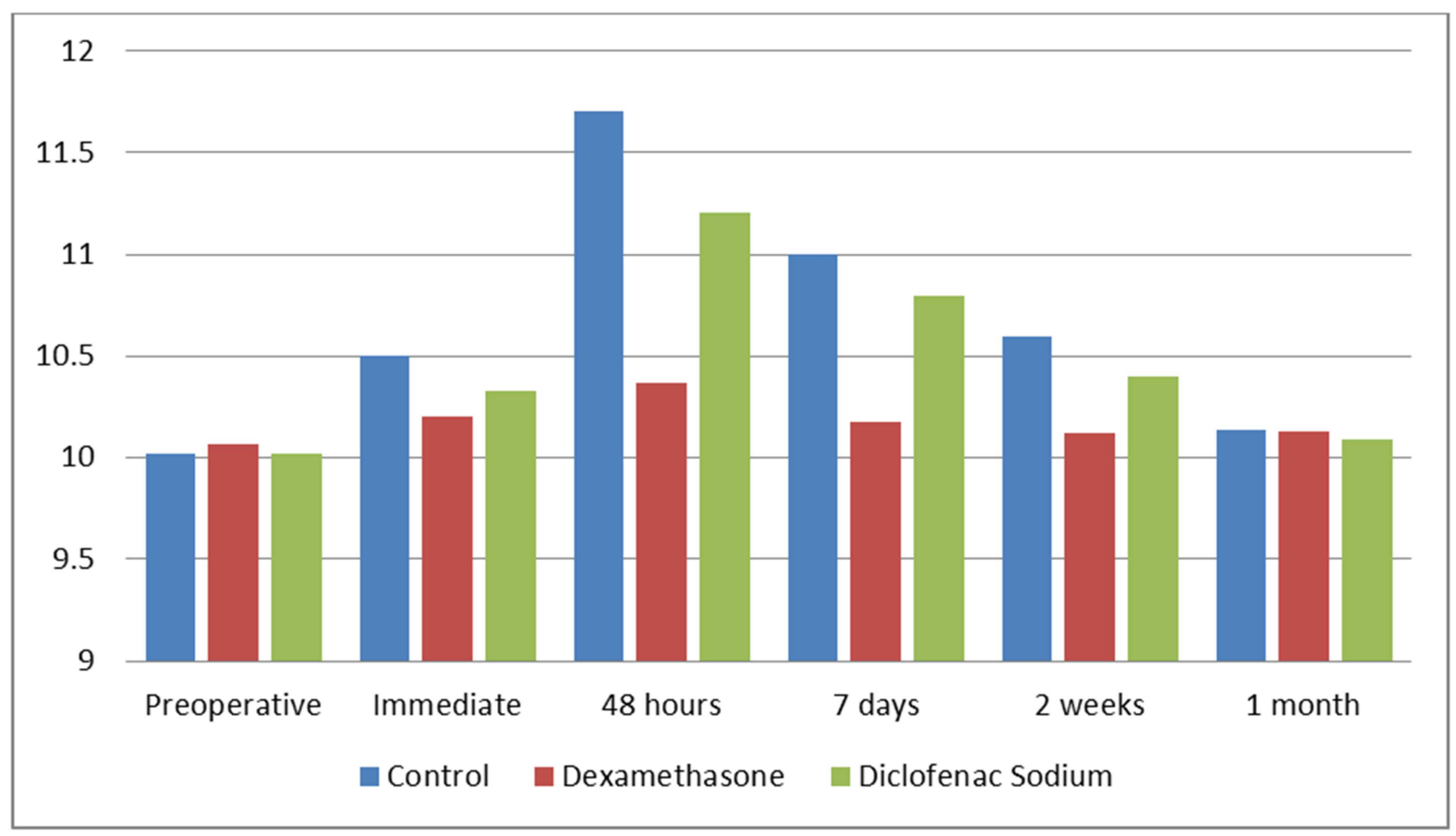

Figure 2. Histogram showing the Mean Gonion-Pognion ( $\mathrm{mm}$ ) for the different tested groups.

Comparing of mean and standard deviation (SD) of Gonion-Ala of nose and outer canthus of eye represented highly significant differences $\mathrm{p} \leq 0.001$ after 48 hour and no significant differences related immediate, 2 weeks and 1 month postoperatively. $\mathrm{p}=0.524 \quad \mathrm{p}=0.293 \quad \mathrm{p}=0.899$ respectively. Non significant differences in all measures in gonion - tragus line.
Measuring of trismus by interincisal distance represented highly significant differences $\mathrm{p} \leq 0.001$ immediate, $48 \mathrm{~h}, 7$ days and 2 week postoperatively (figure 3 ). minimal trismus in Dexamethasone group. Highly significant differences $p \leq 0.001$ in all intervals of VAS extreme pain related to control groups minimal pain in Dexamethasone group (figure 4)

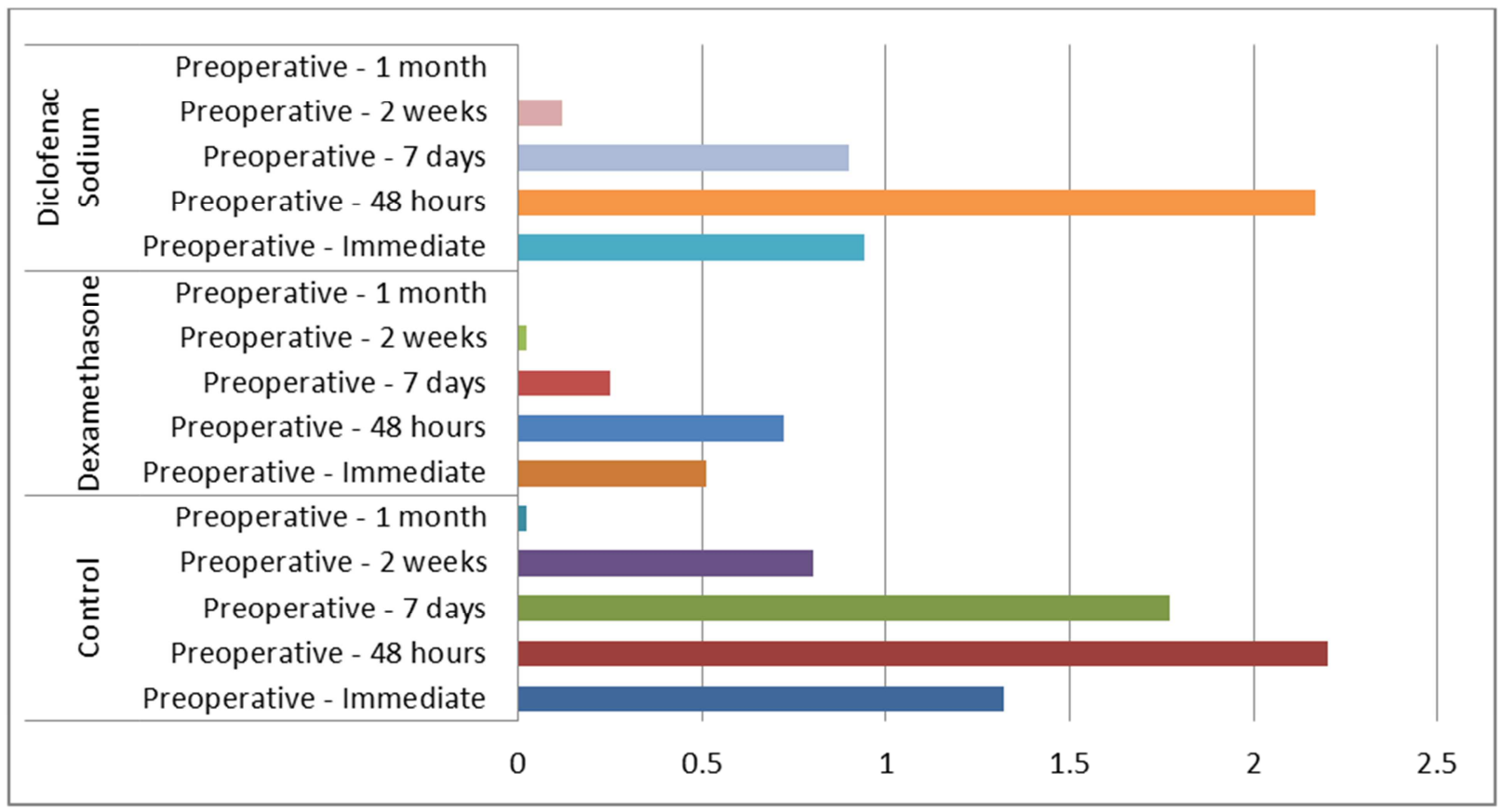

Figure 3. Histogram showing the Mean Mouth Opening ( $\mathrm{mm}$ ) between Pre-operative and each follow-up period for each group. 


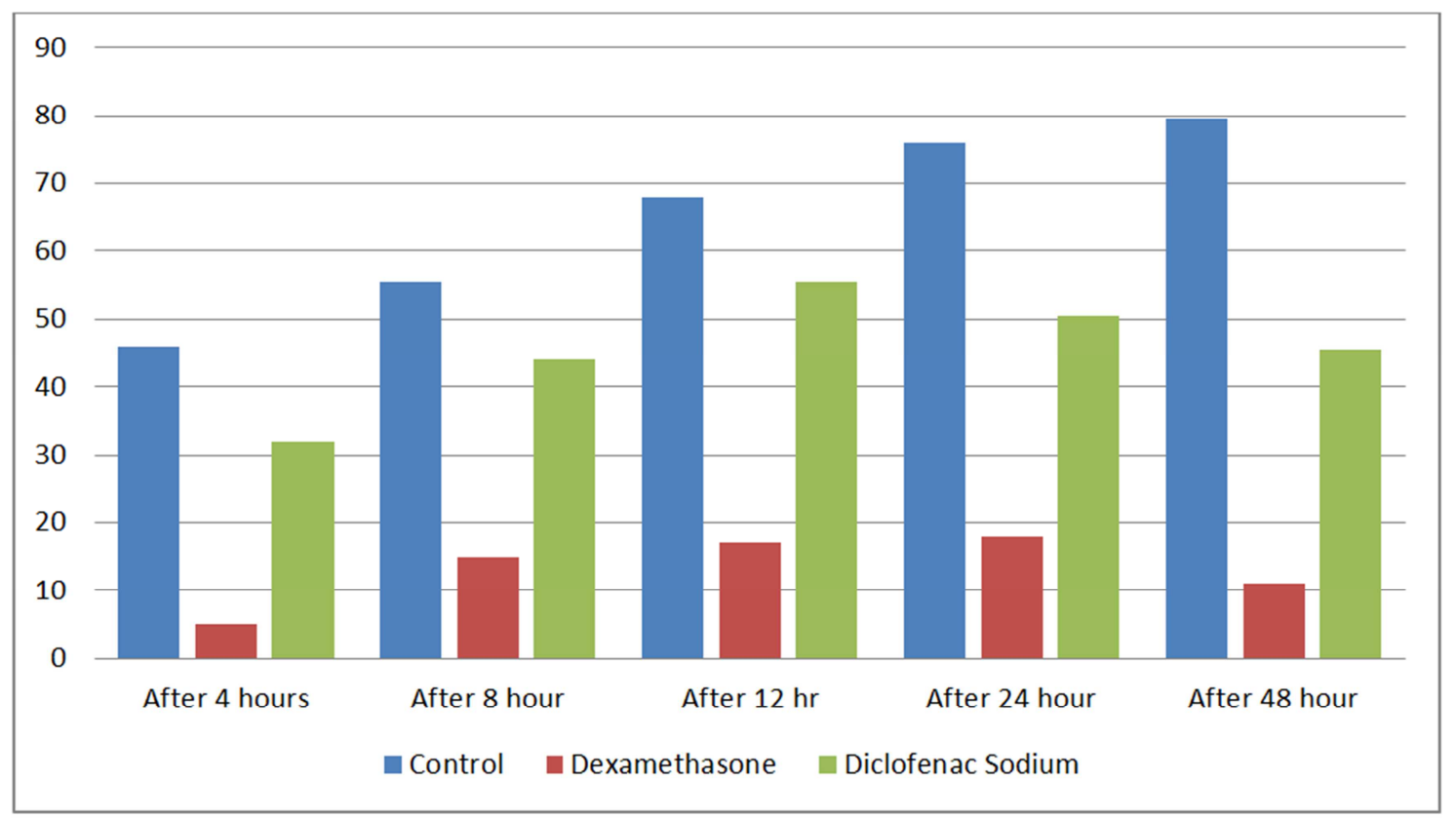

Figure 4. Histogram showing the Mean VAS Score for the different tested groups.

\section{Discussion}

This prospective study was dealing with comparison of effectiveness of submucosal injection of Dexamethasone Sodium Phosphate and Diclofinac Sodium and placebo. The study included sixty patients with age ranged from 18 to 35 years who were admitted randomly into three groups; patients must be free from any systemic diseases or local pathosis associated with impacted molars. Standardized panoramic view was taken preoperatively for each patient to correct classifying them.

Most NSAIDs act as nonselective inhibitors of the enzyme cyclooxygenase (COX), inhibiting both the cyclooxygenase-1 (COX-1) and cyclooxygenase-2 (COX-2) isoenzymes, this inhibition is competitively reversible [17]. Corticosteroids encourage the synthesis of endogenous proteins, which inhibit the enzymatic activation of phospholipase A2, to prevent arachidonic acid releasing by the cell membrane components, with inhibition of the formation of vasoactive substances such as leukotrienes, prostaglandins, or substances related to thromboxane. Glucocorticoids inhibit the formation of COX with inhibition of prostaglandin E2 (PGE2) and prostaglandin I2, thus cortisols and formative analogs have the capability to decrease the physiologic process of inflammation and thereby suppress the development of swelling, redness, pain and tenderness. [18-25]

In current study, submucosal route was chosen to avoid the virulent systemic effect of drugs and increase the concentration of drugs in surgical sites without dissipation them in other sites in body. Giovanni BG et al, [26] who concluded in their study on effecting of Submucosal injection of Dexamethasone sodium phosphate in different dose after the surgical extraction of impacted third molar. Omer W, Waseem K [27] compared effect of submucosal and intramuscular dexamethasone, found great effect of submucosal injection. Also Nandini, Gandhiraj [28] and Nair RB et al, [29] concluded same results.

Facial edema was measured as described by Jadson A et al. [15]. In present research, measurements of facial dimension were performed preoperative, immediately postoperative, 48h, 7days and one mouth postsurgery. Dhanavelu et al. [30] also Janne T. et al.[31] concluded that preoperative submucosal dexamethasone may be preferred to oral, IM and IV routes. Also Herrera-Briones et al. [25] concluded that greater effects appear to be obtained by using parenteral rather than oral administration, Warraich et al. [32] compared between dexamethasone by submucosal injection and no CS administration. Giovanni BG et al, [26] and Francisco Javier et al, [33] There was a significant reduction in edema in both dexamethasone groups comparing with control group in clinical study of Alca ntara et al [34] also Jadson A et al. [15] concluded submucosal preemptive combination of tramadol with dexamethasone more effective than tramadol with diclofenac sodium. Sortino, Cicciù [35] analyzed publications of the last 20 years with a pubmed search, focused on corticosteroid was administered by various routes

These postoperative edema lead to limitation in mouth opening, strain of muscles fiber and compression of nerves, numerous study was dealing with trismus measurement. In this study we measure the distance between upper and lower incisors perioperatively, immediately postoperative, after 48h, 7 days and after one month. Concluded there was significant difference between groups in decreasing trismus especially after $48 \mathrm{~h}$ postoperatively. Patients were given corticosteroids have lowest postoperative pain, these findings were corroborated with some authors like Jadson A et al. [15] 


\section{Conclusion}

Preoperatively submucosal injection of dexamethasone sodium phosphate at surgical site before surgical extraction of lower third molar better reduced the postoperative complication (pain, edema and trismus) than submucosal injection of diclofenac sodium and both were better than placebo injection especially pain and facial edema.

\section{References}

[1] Marciani RD. Complications of third molar surgery and their management. Atlas Oral Maxillofac Surg Clin North Am. 2012 (2):233-51. [PubMed] [Cross Ref]

[2] Osunde OD, Adebola RA, Omeje UK. Management of inflammatory complications in third molar surgery: A review of the literature. Afr Health Sci. 2011;11(3):530-537.

[3] Lopez-Carriches C, Martinez-Gonzalez JM, DonadoRodriguez M. The use of methylprednisolone versus diclofenac in the treatment of inflammation and trismus after surgical removal of lower third molars. Med Oral Patol Oral Cir Bucal. 2006; 11(5):E440-E445.

[4] Beirne. Corticosteroids decrease pain, swelling and trismus. Evidence Based Dent. 2013; 14(4):111.

[5] Shah SA, Khan I, Shah HS. Effectiveness of Submucosal Dexamethasone to Control Postoperative Pain \& Swelling in Apicectomy of Maxillary Anterior Teeth. Int J Health Sci (Qassim). 2011; 5(2):156-165.

[6] Babatunde Olamide Bamgbose, Jelili Adisa Akinwande,Wasiu Lanre Adeyemo. Effects of co-administered dexamethasone and diclofenac potassium on pain, swelling and trismus following third molar surgery. BioMed- center 2005.

[7] Saito $K^{1}$, Kaneko A, Machii $K$, et al. Effectiveness of additional $200 \mathrm{mg}$ of celecoxib on postoperative pain after surgical extraction of third molar. 2012feb; 34(2):314-28. doi: 10.1016/j.clinthera.2012.01.004. Epub 2012 Jan 28.

[8] De Menezes SA'Cury PR. Efficacy of nimesulide versus meloxicam in the control of pain, swelling and trismus following extraction of impacted lower third molar. Int J Oral Maxillofac Surg. 2010 Jun; 39(6):580-4. doi: 10.1016/j.ijom.

[9] Boworn Klongnoi, Pariya Kaewpradub, Kiatanant Boonsiriseth, et al. Effect of single dose preoperative intramuscular dexamethasone injection on lower impacted third molar surgery. Int. J. Oral Maxillofac. Surg. 2012;41: 376-379. 2011 International Association of Oral and Maxillofacial Surgeons.

[10] Brown JD, Daniels SE, Bandy DP, et al. Evaluation of multiday analgesia with etoricoxib in a double-blind, randomized controlled trial using the postoperative thirdmolar extraction dental pain model. J Pain. 2013 Jun; 29(6):492-8. doi: 10.1097/AJP.0b013e318260c144.

[11] Trindade PA, Giglio FP, Colombini-Ishikiriama BL, et al. 2012 Sublingual ketorolac and sublingual piroxicam are equally effective for postoperative pain,trismus,and swelling management in lower third molar removal.

[12] Aznar-Arasa $\mathrm{L}^{1}$, Harutunian $\mathrm{K}$, Figueiredo R, et al. Comparative study of preoperative vs postoperative administration of ibuprofen. International Association of Oral and Maxillofacial Surgeons. Published by Elsevier Ltd. All rights reserved. 2012.

[13] Schlieve T, Kolokythas A, Miloro M. Third Molar Surgery Management of complications in oral and maxillofacial surgery. Chicago: Wiley-Blackwell; 2012:25-33.

[14] Ness G. Impacted teeth. In: Miloro M, Ghali GE, Larsen PE, Waite PD, eds. Peterson's Principles of Oral and Maxillofacial Surgery. 3rd ed. Connecticut: PMPH-USA; 2012:113-114.

[15] Jadson Alípio Santana de Sousa Santos, Luiz Carlos Ferreira da Silva, Thiago de Santana Santos, et al. Comparative study of tramadol combined with dexamethasone and Diclofenac sodium in third-molar surgery. Journal of Cranio-MaxilloFacial Surgery.2012.

[16] Fragiskos FD. Surgical Extraction of Impacted Teeth. In: Schroder Gabriele M, ed. Oral Surgery. Heidelberg: SpringerVerlag; 2007:195-197.

[17] Tiigimae-Saar J, Leibur E, Tamme T. Stomatologija. Comparative study of effect of sublingual administration of piroxicam versus ketorolac on postoperative complication 2010; 12(1):17-22.

[18] Al-Saffar MT. Efficacy of Paracetamol versus Celebrex on the Control of Post Operative Complica-tions of Lower Third Molars. Al-Rafidain Dent J. 2011; 11(1):24-31.

[19] Häggström, Mikael; Richfield, David. "Diagram of the pathways of human steroidogenesis". WikiJournal of medicine. 1 (1). doi:10.15347/wjm/ 2014.0 05. ISSN 2002-4436.

[20] Frye CA "Steroids, reproductive endocrine function, and affect. A review". Minerva Ginecol 61 (6): 541-562. PMID 19942840. (2009).

[21] Pelt AC Glucocorticoids: effects, action mechanisms, and therapeutic uses. Hauppauge, N. Y.: Nova Science. ISBN 9781617287589. (2011).

[22] Revollo JR, Cidlowski JA "Mechanisms generating diversity in glucocorticoid receptor signaling". Ann. N. Y. Acad. Sci. 1179: 167-78. doi:10.1111/j.1749-6632.2009.04986.x.PMID 19906239. (October 2009).

[23] Liapi and Chrousos Chapter 14. Glucocorticoid Therapy and Adrenal Suppression.

[24] Pazirandeh A, Xue Y, Prestegaard T, et al. "Effects of altered glucocorticoid sensitivity in the $\mathrm{T}$ cell lineage on thymocyte and T cell homeostasis". FASEBJ. 2002.

[25] Herrera-Briones FJ, Prados Sánchez E, Reyes Botella C, et al. Update on the use of corticosteroids in third molar surgery: systematic review of the literature. Oral Surg Oral Med Oral Pathol Oral Radiol. 2013; 116(5):e342-e351.

[26] Giovanni Battista Grossi, Carlo Maiorana, Rocco Alberto Garramone, et al. American Association of Oral and Maxillofacial Surgeons J Oral Maxillofac Surg 65:2218-2226, 2007.

[27] Omer Waleed Majid, Waseem Khalid. Effect of submucosal and intramuscular dexamethasone on postoperative sequelae after third molar surgery. 29 October 2010

[28] Nandini, Gandhiraj. Effect of intramuscular and submucosal examethasone on postoperative sequelae after third molar surgical extraction: Comparative study. doi: 10.1016/j.ajoms.2013.09.010. G.D. 2013. 
[29] Nair RB, Rahman NM, Ummar M, et al. Effect of submucosal injection of dexamethasone on postoperative discomfort after third molar surgery. J Contemp Dent Pract. 2013;14(3):401404 .

[30] Dhanavelu P, Shanmugapriyan, Ebenezer V, et al. Dexamethasone for third molar surgery- a review. Int J Pharm Bio Sci 2013; 4(4):9-13.

[31] Janne Tiigimae-Saar, Edvitar Leibur, Tiia Tamme The effect of prednisolone on reduction of complaints after impacted third molar removal. Stomatologija, Baltic Dental and Maxillofacial Journal, 12: 17-22, 2010.

[32] Warraich R, Faisal M, Rana M, et al. Evaluation of postoperative discomfort following third molar surgery using submucosal dexamethasone - Oral Surg Oral Med Oral Pathol Oral Radiol. 2013; 116(1):16-22.
[33] Francisco Javier Herrera-Briones, Estrella Prados Sánchez, Candela Reyes Botella, et al. work on Update on the use of corticosteroids in third molar surgery. (Oral Surg Oral Med Oral Pathol Oral Radiol 2013;116:e342-e351).

[34] Alcântara, S. G. M. Falci, F. Oliveira-Ferreira, et al. comparative study of effect of dexamethasone vs methylprednisolone 40mg on postoperative complication of surgical removal of lower third molar. Pinheiro 2013.

[35] Sortino F, Cicciù, analyzed publications of the last 20 years with a pubmed search, focused on corticosteroid was administered by various routes Dent Res J (Isfahan). 2011 Oct; 8(4):162-71. doi: 10.4103/1735-3327.86031. M. 